\title{
NATURAL PROCESSES FOR THE RESTORATION OF DRASTICALLY DISTURBED SITES ${ }^{1}$
}

\begin{abstract}
David F. Polster ${ }^{2}$
Abstract. Natural processes have been revegetating naturally disturbed sites (landslides, volcanic explosions, earthquakes, etc.) since the advent of terrestrial vegetation about 400 million years ago. Understanding the way these natural processes operate provides a framework for the design of restoration programs for anthropogenic disturbances (mines, industrial disturbances, etc.). The first step in the design of a natural process based restoration program is to identify what it is that is delaying the natural recovery from occurring (filters). Common abiotic stressors (filters) are adverse texture, nutrient status, adverse chemical properties, soil temperature extremes, compaction, adverse micro-site conditions, and excessive erosion. Biotic filters include herbivory, competition, propagule availability, phytotoxic exudates, facilitation, and adverse species interactions. Once the filters that are preventing recovery are identified and addressed, the natural processes will operate to restore the site. Care must be taken not to solve one problem by creating another. Traditional grass and legume seeding has been used to control erosion on many reclamation sites. However, the seeded cover has been found to restrict the growth of woody species so if a forest is what the restoration program is directed at, then seeding with grasses and legumes may be inconsistent with desired results. Making sites rough and loose can address a number of filters (compaction, excess erosion, lack of micro-sites, soil temperature extremes) and costs about a third of the cost of traditional hydroseeding. In many cases, there are ample seed sources nearby and making a mine site rough and loose with the application of large woody debris at a rate of $100 \mathrm{~m}^{3} /$ ha (determined from studies in Northern Alberta) can initiate the recovery process. Pioneering species often have effective seed dispersal mechanisms so creating the right habitat can result in the establishment of the pioneering species that are adapted to the local conditions. Practices such as making sites rough and loose (like trees in a forest turning up the soil) and scattering large woody debris on the area can initiate recovery on drastically disturbed sites.

By creating conditions (rough and loose with woody debris) that foster invasion by pioneering species as well as controlling erosion means that generally the need for seeding or planting is eliminated. Large bulldozers can be used to reslope waste dumps. The incorporation of wrap around dumps in mine design reduces the cost of resloping. Large excavators can be used to make the resloped waste dumps rough and loose and to scatter the woody debris. Using natural recovery processes reduces the costs associated with traditional restoration of large disturbances.
\end{abstract}

${ }_{1}$ This paper was presented at the 2016 National Meeting of the American Society of Mining and Reclamation, Spokane, WA Reclaiming the West June 4-9, 2016. R.I. Barnhisel (Ed.) Published by ASMR, 1305 Weathervane Drive, Champaign, IL 61821.

${ }^{2}$ David Polster, M.Sc., R.P.Bio. is a restoration ecologist with Polster Environmental Services Ltd., 6015 Mary Street, Duncan, BC, V9L 2G5 CANADA.

Journal American Society of Mining and Reclamation, 2016 Volume 5, Issue 2 pp 77-90

DOI: http://doi.org/10.21000/JASMR16020077 


\section{Introduction}

Historically mine reclamation has developed from the fields of forestry and agriculture (including soil science) (Polster, 1989). Unfortunately, many restoration strategies have not been broadly tested, and mine reclamation continues to rely on historical treatments that do not necessarily result in a desirable ecosystem. More recently, restoration ecology has offered strategies for the reclamation of large disturbances (Tongway and Ludwig, 2011). The primary objective of this paper is to show how natural processes can be used as a framework for mine reclamation. Natural processes have been restoring natural disturbances since the advent of terrestrial vegetation over 400 million years ago (Holmes, 1965). Understanding these natural recovery processes allows new practices for mine reclamation to be identified and researched (Polster, 2013). These practices are based on the idea that the most effective strategies are those that assist the natural recovery processes. Ecological restoration is defined as the process of assisting the recovery of an ecosystem that has been degraded, damaged, or destroyed (SERI, 2004). The trick then becomes one of determining what things can be done to assist the recovery and what things should not be done to avoid preventing recovery. This is much like a small cut on your hand - there are things you can do to help your hand heal, put on antiseptic, a bandage and keep it clean, and there are things that you can do that will prevent or hinder the recovery of your cut hand, i.e., shovel out the chicken coop and get the cut infected. However, we cannot force our hand to heal, and neither can we force an ecosystem to recover.

Understanding the processes of ecosystem degradation can provide clues for treatments that can be used to halt or reverse degradation and assist in the recovery. Hobbs and Suding (2009) suggest that degradation can be divided along two lines, abiotic and biotic. Abiotic degradation is defined as those degrading factors that are associated with the physical aspects of the ecosystem. Grazing elk or invasive species are biotic degrading agents. These degrading forces are discussed in more depth later in this paper.

Various stressors can be thought of as filters (Temperton et al., 2004) to recovery. That is, they may prevent the recovery of a full suite of species, but allow some species to establish. For instance a compacted waste rock dump surface (abiotic stressor) may prevent the growth of a healthy forest, but allow weedy species such as Mullein (Verbascum thapsus L.) to grow freely. Similarly, hungry elk or deer (biotic stressor) may prevent the growth of Western Red Cedar (Thuja 
plicata Donn ex D. Don) but may allow Red Alder (Alnus rubra Bong.) to thrive. Some species are filtered out while others can establish.

Natural processes work in conjunction with ecological filters (stressors), creating plant, and animal communities suited to the local conditions. By looking at how these natural successional processes operate under a given set of stressors, ideas for the restoration of drastically disturbed sites can be generated. For instance, soils and plant communities can develop on glacially compacted basal tills after the accumulation of organic matter and the loosening of the soils by weathering and root systems of pioneering species, particularly nitrogen-fixing woody species (e.g., Alnus spp.). Eventually soils on these sites can support forests. Natural processes such as trees blowing over in storms with large root masses coming up with the stump can loosen soil and move non-mobile nutrients such as $\mathrm{K}$ and $\mathrm{P}$ to the surface for subsequent use by growing plants. By mimicking the natural successional processes that have evolved for treatment of disturbed sites, solutions to anthropogenic disturbances can be identified.

This paper is organised to present the common filters that are found at most mine sites and the natural processes that are potential solutions to these filters. The paper presents strategies that have been found to result in for the establishment of suitable vegetation covers on mine sites in Western Canada, that will build soils and create self-sustaining ecosystems on the disturbed ground.

\section{Natural Recovery Processes}

Polster (2013) listed eight abiotic and six biotic filters to recovery. The mining industry typically encounters the following abiotic constraints to recovery; compaction (haul roads and dump platforms), steep slopes (dump slopes), adverse texture (toe of waste rock dumps), adverse chemical properties ( $\mathrm{pH}$ extremes, excess metals, etc.), low nutrient status (most mining wastes), soil temperature extremes (dark coal wastes), excessive erosion (many sites), and lack of microsites (smooth surfaces). Some of the biotic filters are also found at mines; excess herbivory (from high deer and elk populations), competition (from seeded agronomic grasses and legumes), propagule availability (with large disturbances), phytotoxic exudates (from weedy species like Knapweed), facilitation, and species interactions (adverse ecological interactions). Many of these filters may act together to limit recovery, for instance steep slopes and adverse textures may be 
found on waste rock dump slopes. Similarly, treatments that can ameliorate one filter may also help with another.

Compaction is probably the most common filter found at mines. Traditional end dumping with trucks running on the dump platform and spreading materials with bulldozers creates compaction in the soils and prevents healthy growth of vegetation. Using an excavator to prepare the surface of the compacted area can be an effective way of alleviating compaction. The excavator can make rough and loose configurations (see Fig. 1 and 2) by opening holes on the site, and dumping the material that is generated from the holes in mounds between the holes. The excavator, using a digging bucket (not a clean-up bucket), takes a large bucket full of material and places it to the left of the hole that was just opened, half a bucket width from the hole so it is half in and half out of the hole. Rocks are fine to include as these tend to create additional heterogeneity. A second hole is then excavated half a bucket width to the right of the first hole, and material from this hole is then placed between the first and second holes. A third hole is now opened half a bucket width to the right of the second hole, with the excavated soil placed between the second and third holes. Care should be taken when excavating the holes to shatter the material between the holes as the hole is dug. The process of making holes and dumping soil is continued until the reasonable operating swing of the excavator is reached. The excavator then backs up the width of a hole and repeats this process, being sure to line up the holes in the new row with the space between the holes (mounds) on the previous row. Rough and loose surface configurations can be used on recontoured dump slopes to control erosion and provide suitable sites for vegetation establishment. Making a former coastal hydroelectric dam and penstock site rough and loose and scattering woody debris resulted in the natural establishment of an average of 5,412 alder plants ha ${ }^{-1}$ the first year after treatment ( 50 plots, $\mathrm{SD}=57.08$ seedlings), while in the second year an average of 8,550 seedlings ha-1 were found (repeated sampling of same plots, SD $=94.50$ seedlings) with 67 other species. In 2016, the number of alder plants had levelled off to $6,162 \mathrm{ha}^{-1}(\mathrm{SD}=45.77)$ with 75 other species including conifers in 80 percent of the plots suggesting successional processes are moving along. Cost at a large northern mine for making sites rough and loose were found to be about $\$ 700 /$ ha based on an average production rate of 4 hours $\mathrm{ha}^{-1}$. 

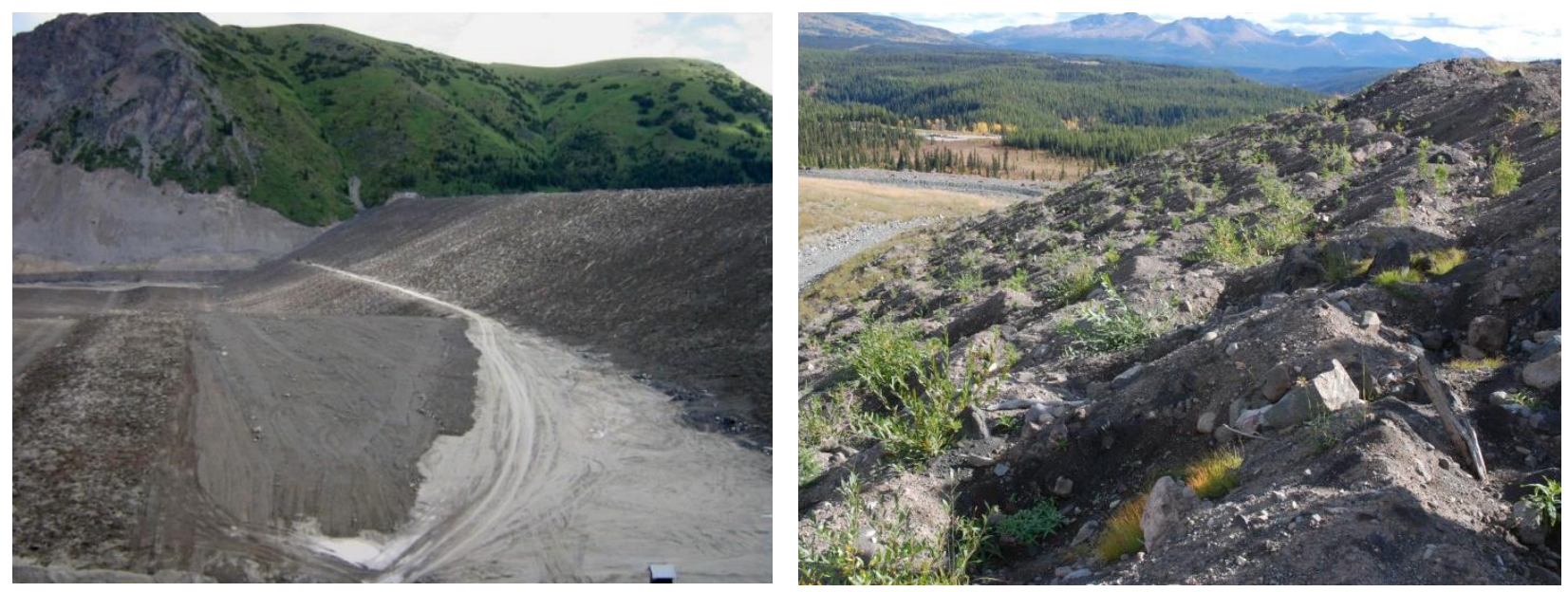

Figure 1 and 2. Rough and loose surface configurations have been used on this tailings dam (left) as well as the waste dumps (right) at a northern mine. Making sites rough and loose is less than one third the cost of traditional hydroseeding.

Steep slopes are common at many mines in mountainous areas. Waste-rock dumps are constructed by dumping wastes around or over the rim of the dumps and then pushing these materials over the edge of the dump slope, forming angle-of-repose slopes. The natural analogue of waste rock dumps are talus slopes (Polster and Bell, 1980). These slopes tend to revegetate very slowly as most of the material on the slope is too coarse to support plants. The materials at the top of the slope are fine textured and will support plant growth, but this area is continually bombarded by materials from the cliffs above. In the middle of the slope, the materials are too coarse to hold moisture and therefore will not support vegetation. At the bottom of the slopes, the spaces between the large rocks slowly fill with bryophytes and organic matter and eventually will support the growth of higher plants. The slow erosion of the fine textured materials from the top over the middle portion of the slope will eventually allow vegetation to establish. Eventually, the areas of adverse texture are addressed by either organic matter collecting between the large rocks or by fines washing down from above. This process can be greatly expedited at mine waste dumps by pushing the fines from the top of the slope over the face and down to the toe of the slope.

Designing mine waste dumps to foster re-sloping and subsequent restoration is an important part of the design process. Wrap-around dumps can greatly reduce the costs associated with resloping (Milligan and Berdusco, 1978). Incorporating restoration considerations in the mine design process can reduce costs and build social license. By facilitating natural processes that will 
re-establish the successional trajectories that operate in the region, the restoration of mine waste dumps can be cost-effective.

The low nutrient status of most mining wastes can limit the growth of some plants. However, pioneering species, including those that are associated with nitrogen fixing bacteria, have evolved to grow in areas of low nutrients. The use of early pioneering species as the principle revegetation species on mining sites (Polster, 1989) eliminates the need for fertilizers while providing a vegetation cover that will build healthy soils on the relatively inert materials left from mining.

Adverse chemical properties of waste materials (tailings and waste rock) at some mines require that these materials be isolated from the environment. Acid rock drainage and metal leaching is a problem at some mines that requires that cover systems be established to isolate the offending materials (O'Kane et al., 2001). The key to the design of waste rock covers is to ensure that there is ample clean material on top of the material that is used to seal the wastes to allow vegetation to grow freely. The idea that woody species can be prevented from growing on a thin cover, thereby reducing the immediate cost of the cover, is false. There is a risk that the integrity of the cover will be breached by the eventual growth of woody species in these areas, and the costs of not providing a proper cover will be passed on to the future mining industry either as a direct cost or as the loss of social licence and the refusal of society to permit the opening of new mines. Most woody species in western North America need at least two meters of growth medium to support woody vegetation. This is on top of the materials that are used to seal the wastes.

Dark substrates are a common problem at many coal mines. In the hot summer sun these materials may reach temperatures that are too extreme for plant growth. Excess erosion and a lack of microsites are other common problems at many mines. Making the surface rough and loose and covering the surface with $100 \mathrm{~m}^{3} /$ ha of woody debris (Vinge and Pyper, 2012) can control erosion and create ideal sites for vegetation establishment while providing a long term nutrient source for the new forest. Woody debris can provide an important habitat for a variety of animals as well as plants (Craig et al., 2014).

Biotic filters at mines may be of less importance than the abiotic filters. However, competition by seeded agronomic grasses and legumes can severely restrict woody species growth (Polster, 2010). Seeded grasses and legumes have historically been part of the mine reclamation tool kit (Ziemkiewicz, 1977). However, long-term studies at mines throughout Western Canada have 
shown that seeding mining wastes with agronomic grasses and legumes provides habitat for small mammals that eliminate woody species (Green, 1982). Making sites rough and loose, adding woody debris, and seeding or planting in pioneering woody species avoids the problems of seeded agronomic grasses and legumes. In addition, the cost of making sites rough and loose and scattering woody debris is about one third of the cost of traditional seeding with agronomic species.

\section{$\underline{\text { Restoration Strategies }}$}

Mimicking the natural recovery processes that have evolved to address naturally disturbed sites is the most effective strategy for treatment of mining disturbances. By working with the natural systems that have evolved to restore natural disturbances such as landslides, volcanic eruptions, glaciation, and other major disturbances, the restoration program can take advantage of these natural recovery processes. At a dam site discussed above where the dam and related infrastructure (penstock) was removed, large disturbed areas were left. The site was treated with woody debris and the rough and loose technique (Fig. 3) and no other treatments. Now, four years after the treatment there are 6,162 red alder (Alnus rubra Bong.) (a pioneering species that fixes nitrogen) established plants per hectare along with 75 other species including western hemlock (Tsuga heterophylla (Raf.) Sarg.), Western Redcedar (Thuja plicata Donn ex D. Don) and Douglas-fir (Pseudotsuga menziesii (Mirb.) Franco) (see Fig. 4). All of these have established without any planting work by humans. By taking advantage of the erosion-controlling attributes of the rough and lose ground covered with woody debris (a waste material that would have had to be disposed of) the project saved hundreds of thousands of dollars of planting work as well as the costs associated with the slash disposal. Rough and loose surface configurations cost about $\$ 700 /$ ha of machine time ( 4 hours/ha) to install (costs may vary depending on location and conditions of the site treated). 

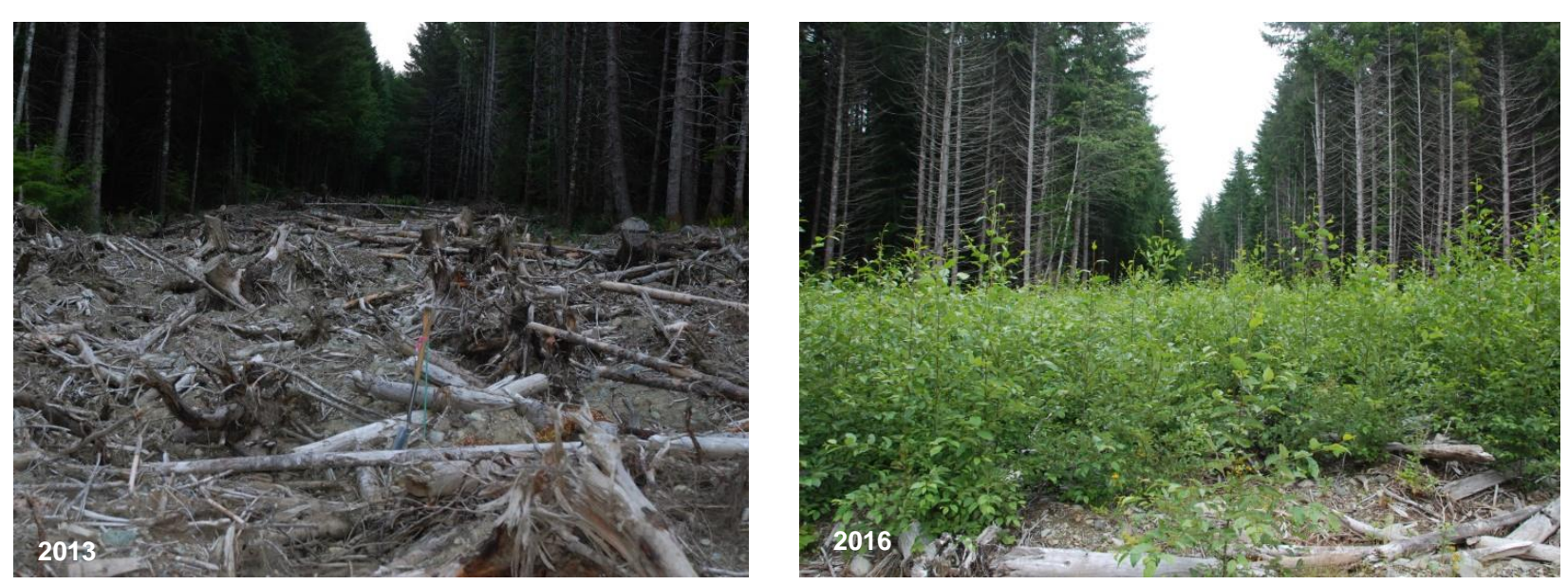

Figure 3 and 4. This former dam penstock right-of-way was made rough and loose with woody debris applied (left). The pioneering Red Alder (Alnus rubra Bong.) seeded in naturally and now covers the area (right), building soils and providing habitat for later successional conifers.

Where large distances are involved between the seed producing pioneering species and the areas needing restoration, propagules (seeds, plants, cuttings, etc.) of the pioneering species need to be provided. Seeding with pioneering woody species such as alder can be a very effective way to cover large areas at low cost. Pioneering species such as alder produce abundant seeds so collection of seeds locally is generally easy. The seeds of poplars and willows are wind-blown and may not retain viability for long. Although these species may start to grow naturally on a site, establishing these species from cuttings can be very effective. The important aspect of this process is to use the pioneering species for the region, even if eventually a late successional forest is the desired outcome. Later successional species will establish under the protection of the pioneering species. The successional sequence of deciduous followed by conifers is very common in Western North America.

The growth of later successional forest species is enhanced by the presence of pioneering species. Pioneering species are often associated with nitrogen fixation, as this tends to be a limited element in early successional ecosystems. Lichens may be the first plants to establish on recent lava flows and other areas where nitrogen is lacking (Henriksson and Simu, 1971). In forest ecosystems of the Pacific Northwest, alder plays an important role in creating conditions that will encourage the future forest (Sanborn et al., 1997; Peterson et al., 1996). The canopy of alder allows the conifers underneath to grow significantly better than without the canopy (Polster and Dubois, 2007). The canopy of alder keeps the understory cooler and moister on hot summer days as the 
transpirational loss of moisture from the photosynthesising alder is evaporated from the stomata of the alder, taking the latent heat of vaporisation from the surrounding air, thus allowing the conifers to maintain photosynthetic activity during the hot days of summer. In the winter, the deciduous pioneering species lose their leaves, allowing the winter sun to drive photosynthesis in the evergreen conifers. Following the natural successional patterns in the establishment of vegetation on mine sites allows the vegetation to take advantage of the improved growth conditions for a set of species in the successional stage in which it naturally occurs.

Erosion is a common problem at many mines. Elaborate (and costly) sediment ponds and erosion control measures are employed to limit the discharge of sediment to local water bodies. Understanding why erosion is minimal in natural systems can provide clues for the management of erosion at mine sites. Erosion is an ongoing natural process; however, when bare sites are exposed to the erosive elements (water, wind, frost, etc.) increases in erosion can occur. Soil loss through erosion has been studied for many years. The universal soil loss equation (Wischmeier and Smith, 1965) uses the factors that influence erosion and should be used in managing erosion.

Compaction is one of the main causes of erosion. Water flowing down a compacted haul road can pick up sediment and transport it down the slope. Slope length and steepness are other factors as is the soil texture (cohesionless fine silts are the most highly erosive soils). The soil surface configuration is also important. All of these factors can be managed by using the rough and loose surface treatment. Rough and loose ground encourages water to soak in rather than run across the surface. Coarse woody debris $\left(100 \mathrm{~m}^{3} / \mathrm{ha}\right)$ also controls the movement of water across the surface. Slowing the flow of water in ditches can remove the erosive energy of the water, again promoting the movement of surface water into the groundwater system. Stem cuttings of willow can be used in ditches to slow water flows and allow sediment to drop out. It is useful to note that in most natural ecosystems water soaks into the soils and does not flow across the surface. Springs and seeps occur where this water exits the groundwater system. Creating situations where surface waters have the opportunity to soak into the soil is one of the most effective erosion control strategies. Many plants are funnel shaped so that rain that falls on the leaves and stems is naturally directed to the base of the plant and into the soil.

Competition can be a problem at mine sites where seeded grasses and legumes have been applied. In most cases, natural successional processes do not include a cover of herbaceous species 
as dense as the seeded cover found at many mines. This seeded cover can prevent the recovery of the pre-disturbance ecosystems at the mines where they have been established. Using non-native, aggressive seeded grasses and legumes to control erosion is not a good idea as it precludes the ongoing vegetation development on the site.

Natural processes can provide effective strategies for the restoration of mines and other large disturbances. Treatments such as making the surfaces rough and loose and scattering woody debris (Fig. 3) on the rough and loose surface can assist with the control of erosion, reduction of compaction, providing small north and south facing slopes (to avoid high temperatures associated with dark substrates), and creating conditions that foster the establishment of vegetation (Fig. 4). By following the natural successional patterns in the establishment of vegetation the right species will establish at the right time in the right place. By creating a diversity of habitats through the rough and loose surfaces a diversity of species will establish. Species that require moister locations might establish in the hollows between the hills, while the species that favour drier conditions could be found on the hills. There are species that grow on rotting wood. These would be found on the scattered woody debris. Similarly, species that require passing through the gut of a bird to germinate (scarified) will be found near the woody debris areas where there are perches for birds that eat those seeds. By creating a diversity of habitats a diversity of species will establish and make the established habitats their home.

Creation of heterogeneous reclaimed areas will provide diverse ecosystems that will help to build resilience (Holling, 1973) in the former mine site area. This will ensure that the established ecosystems are self-sustaining since there will always be a progression of appropriate species on the sites. By using pioneering species to initiate the recovery processes (as natural systems do) the right subsequent species will show up in the right location. The ability of natural recovery processes to create the conditions for the establishment of the species that are best suited for the conditions of the site being vegetated should not be overlooked in the development of restoration strategies for drastically disturbed sites. The ability of natural systems to recover from disturbances such as fires, floods, landslides, and lava flows can be applied to the recovery from mining disturbances.

Natural systems can be directed to recover in specific ways to foster human uses of the land. For instance, if a reclaimed mine is to be returned to a forestry use, observing how forests recover 
from natural disturbances is an excellent first step in defining the appropriate restoration strategy for the site. On Vancouver Island, the Quinsam Coal Mine is located in one of the best climatic areas for growing Douglas-fir. The end land use for the mining disturbances was determined to be forestry. Test plots that were established in 1982 and re-evaluated in 2007 showed that the growth of Douglas-fir trees with a canopy of Red Alder was significantly better than in the adjacent cut blocks where the alder was discouraged (Polster and DuBois, 2007). A strategy of growing a 50:50 mix of Douglas-fir and Red Alder at a rate of 2,400 stems /ha (normal stocking rate in the region is about 700 stems/ha of Douglas-fir) was selected to create a profitable reclamation program. The Douglas-fir and Red Alder will be allowed to grow for about 25 years at which time the stems will be about $30 \mathrm{~cm}$ in diameter. At that point, the Douglas-fir that has been growing below the canopy of Red Alder will start to get above the alder and will over the next 10 to 15 years shade out the alder. However, the Douglas-fir trees will be at a density of 1,200 stems/ha and will start to compete with each other. Both the Douglas-fir and Red Alder will have straight, unbranched stems because of the dense stocking. All of the alder will be harvested at year 25 and used for flooring and furniture making, while half of the Douglas-fir will be harvested and sold as veneer logs (for making plywood). The remaining Douglas fir will be allowed to grow for another 125 years so that the benefits of an "old growth" forest can be enjoyed. The stems of these trees will be knot free and will command a high price for flooring and other high value uses. By mimicking the natural recovery processes with the alder providing the habitat for the young fir trees, the benefits of improved growth can be translated into profit for the mining company.

\section{Conclusions}

Natural processes have been rebuilding damaged ecosystems for millions of years. These processes provide the best available model for the restoration of large mining disturbances. By addressing the filters that would prevent recovery (compaction, steep slopes, adverse textures, etc.) and providing the pioneering species (either naturally, if seed sources are available, or by planting) that start the recovery processes, the establishment of sustainable restored ecosystems on the mining disturbances can be assured. The natural processes that are at the foundation of this approach are available for free by creating the right conditions for their development. Natural successional processes will ensure an appropriate vegetation cover on the degraded sites, building soils and replacing species as the ecosystems mature. By using pioneering species to start the process the high cost of topsoil replacement is not needed. Pioneering species will build suitable 
soils directly on waste rock as long as the soil textures are suitable. These same pioneering species will create the habitat needed for later successional species (generally conifers in most of boreal Canada). These species will generally establish naturally, although in some cases where seed sources are distant from the restoration sites, planting may be needed. Providing the context for natural processes to operate is the primary objective of the restoration practitioner. Generally fancy seed mixes, elaborate fertiliser regimes, or soil replacements (except for prairie restoration) are not needed. The natural recovery processes can do the work.

\section{$\underline{\text { Literature Cited }}$}

Craig, M.D., A.H. Grigg, R.J. Hobbs, and G.E. Hardy. 2014. Does coarse woody debris density and volume influence the terrestrial vertebrate community in restored bauxite mines? Forest Ecology and Management, Vol. 318, pp. 142-150.

http://dx.doi.org/10.1016/j.foreco.2014.01.011

Green, J.E. 1982. Control of vegetation damage by small rodents on reclaimed land, in Proceedings $6^{\text {th }}$ Annual British Columbia Mine Reclamation Symposium, Vernon, BC, Technical and Research Committee on Reclamation, Ministry of Energy Mines and Petroleum Resources, and The Mining Association of British Columbia, Victoria, BC.

Henriksson, E. and B. Simu. 1971. Nitrogen fixation by lichens, Oikos. Vol. 22(1), pp. 119-121. http://dx.doi.org/10.2307/3543371

Hobbs, R.J. and K.N. Suding. 2009. New models for ecosystem dynamics and restoration, Washington, DC: Island Press. 352 pp.

Holling, C.S. 1973. Resilience and stability of ecological systems. Annual Review of Ecological Systems. 4: 1-23. http://dx.doi.org/10.1146/annurev.es.04.110173.000245

Holmes, A. 1965. Principles of Physical Geology. Thomas Nelson and Sons (Canada) Ltd. Don Mills, Ontario. 1288 pp.

Milligan, A.W. and R. J. Berdusco. 1978. Waste dumps - design, contouring, and vegetation Kaiser Resources Ltd. Operations. Proceedings of the $2^{\text {nd }}$ Annual British Columbia Mine Reclamation Symposium. Vernon, B.C. Technical and Research Committee on Reclamation. BC Ministry of Energy, Mines and Petroleum Resources, Victoria, BC. 
O'Kane, M., S. Januszewski, and G. Dirom. 2001. Waste rock cover system field trials at the Myra Falls operations - a summary of three years of performance monitoring, in Proceedings $25^{\text {th }}$ annual British Columbia Mine Reclamation Symposium, 24-27 September, Campbell River, BC, Technical and Research Committee on Reclamation, BC Ministry of Energy, Mines and Petroleum Resources, Victoria, BC.

Peterson, E.B., G.R. Ahrens, and N.M. Peterson. 1996. Red alder managers' handbook for British Columbia, Canadian Forestry Services and BC Ministry of Forests, FRDA II Report No. 240, Victoria, BC.

Polster, D.F. 1989. Successional reclamation in Western Canada: new light on an old subject, paper presented at the Canadian Land Reclamation Association and American Society for Surface Mining and Reclamation Conference, 27-31 August, Calgary, Alberta. http://dx.doi.org/10.21000/jasmr89010333

Polster, D.F. 2010. Long term reclamation monitoring of vegetative covers at the Island Copper Mine, Port Hardy, BC, paper presented at the BC Technical and Research Committee on Reclamation, BC Mine Reclamation Symposium and the Canadian Land Reclamation Association Meeting, 20-23 September, Courtenay, BC.

Polster, D.F. 2013. Processes and functions: a new approach for mine reclamation, paper presented at the BC Technical and Research Committee on Reclamation, BC Mine Reclamation Symposium, 16-19 September, Vancouver, BC. BC Ministry of Energy, Mines and Petroleum Resources, Victoria, BC.

Polster, D.F. and M.A.M. Bell. 1980. Vegetation of talus slopes on the Liard Plateau, British Columbia, Phytocoenologia, Vol. 8(1) pp. 1-12.

Polster, D.F. and C. Dubois. 2007. Quinsam Coal Mine reclamation 25 years of reclamation experience. In Proceedings of the $31^{\text {st }}$ Annual British Columbia Mine Reclamation Symposium, 17-20 September, Squamish, BC, Technical and Research Committee on Reclamation, BC Ministry of Energy, Mines and Petroleum Resources, Victoria, BC.

Sanborn, P., R. Brockley, and C. Preston. 1997. Ecological role of Sitka alder in a young lodgepole pine stand, Forest Research Note \#PG-10, British Columbia Ministry of Forests, Prince George, BC. 
SERI. 2004. The SER Primer on Ecological Restoration. Version 2. October, 2004. Science and Policy Working Group, October, 2004. Society for Ecological Restoration International. Washington DC, viewed 12 January 2015 (http://www.ser.org/resources/resources-detailview/ser-international-primer-on-ecological-restoration)

Temperton, Vicky M., Richard J. Hobbs, Tim Nuttle, and Stefan Halle. (2004) Assembly rules and restoration ecology, Washington, DC: Island Press. 439 pp.

Tongway, D.J. and J.A. Ludwig. 2011. Restoring disturbed landscapes: putting principles into practice, Washington, DC: Island Press. 189 pp. http://dx.doi.org/10.5822/978-1-61091-007-1

Vinge, T. and M. Pyper. 2012. Managing woody materials on industrial sites: meeting economic, ecological and forest health goals through a collaborative approach, Department of Renewable Resources, University of Alberta, Edmonton, Alberta. 32 pp.

Wischmeier, W.H. and D.D. Smith. 1965. Predicting rainfall-erosion losses from cropland east of the Rocky Mountains, Agr. Handbook No. 282, Washington, DC: US Govt. Printing Office. $47 \mathrm{pp}$.

Ziemkiewicz, P.F. 1977. A comprehensive reclamation research program on coal mining disturbed lands, Proceedings of the $1^{\text {st }}$ Annual British Columbia Mine Reclamation Symposium, 16-18 March, Vernon, BC. BC Ministry of Energy, Mines and Petroleum Resources, Victoria, BC. 